
\title{
Competência midiática: o ativismo dos fãs de The Handmaid's Tale
}

MEDIA LITERACY: THE ACTIVISM OF FANS OF "THE HANDMAID'S TALE"

\section{Daiana Sigiliano}

Mestre em Comunicação pela Universidade Federal de Juiz de Fora. Membro do grupo do Grupo de Pesquisa em Redes, Ambientes Imersivos e Linguagens da Universidade Federal de Juiz de Fora e do Grupo de Pesquisa em Tecnologia, Comunicação e Ciência Cognitiva da Universidade Federal do Amapá. Vice-coordenadora do Observatório da Qualidade no Audiovisual. Pesquisadora da Rede Obitel e da Rede de Pesquisa Aplicada Jornalismo e Tecnologias Digitais.

E-mail: daianasigiliano@gmail.com

\section{Gabriela Borges}

Mestre e Doutora em Comunicação e Semiótica pela PUC-SP, com estágios nas Universidades Autônoma de Barcelona, Dublin Trinity College e Algarve. Pós-doutora pela Universidade do Algarve, em Portugal. Professora e coordenadora do Programa de Pós-Graduação em Comunicação da Universidade Federal de Juiz de Fora. Coordenadora do Observatório da Qualidade no Audiovisual e integrante da Rede Euroamericana de Alfabetização Midiática, sendo coordenadora da equipe brasileira.

E-mail: gabriela.borges@ufjf.edu.br

Recebido em 6 de fevereiro de 2018. Aprovado em 12 de março de 2018.

\section{Resumo}

A competência midiática envolve o domínio de conhecimentos, habilidades e atitudes dos indivíduos em relação ao conteúdo. Nesse sentido, o fenômeno contribui para a autonomia e o desenvolvimento da capacidade crítica dos cidadãos. A partir deste aporte teórico, este artigo tem como objetivo analisar as dimensões da competência midiática que estão em operação nos protestos organizados pelos fãs de The Handmaid's Tale. Conclui-se que, a partir do universo ficcional da trama, os telespectadores ávidos se engajam em prol dos direitos das mulheres e da igualdade de gênero.

Palavras-chave: Competência midiática. Ativismo. The Handmaid's Tale.

$106 \frac{\text { Comunicação \& Inovação, PPGCOM/USCS }}{\text { v. 19, n. } 40 \text { (106-122) maio-ago } 2018}$ 


\section{Abstract}

The media literacy involves the mastery of consumer's knowledge, skills and attitudes in relation to content. In this context, the phenomenon contributes to the autonomy and development of critical capacity of citizens. This is an article that aims to analyze the dimensions of media literacy that are in operation in protests organized by fans of The Handmaid's Tale. It is concluded that, from the plot fictional universe, avid viewers engage in favor of women's rights and gender equality.

Keywords: Media Literacy. Activism. The Handmaid's Tale.

\section{Introdução}

Além de ter alterado os processos criativos, industriais e tecnológicos que envolvem as narrativas ficcionais seriadas, a cultura da convergência trouxe novas possibilidades para o público ávido. ${ }^{1}$ De acordo com Pearson (2010) e Booth (2010), o atual ecossistema de conectividade introduziu formas até então inéditas de sociabilidade e produção de conteúdo na cultura de fãs.

Bennett (2014) pontua que na contemporaneidade a comunicação e a influência dos fãs nos fluxos de mídia foram ampliados. A autora afirma que a internet e, principalmente, a emersão das redes sociais digitais permitiram o desenvolvimento de comunidades mais segmentadas e a troca instantânea de informação. Nesse sentido, os universos ficcionais das narrativas seriadas podem ser analisados minuciosamente à medida que as cenas vão ao ar na televisão.

Criada em 2006, a Wikia - Home of Fandomé a maior plataforma colaborativa de fãs do mundo. Atualmente, o site contém 335 mil páginas destinadas a filmes, vídeo jogos, livros e programas televisivos e recebe 185 milhões de acessos mensais. Todo o conteúdo vinculado na plataforma é elaborado de maneira colaborativa entre os membros. Além de abrangerem informações gerais sobre as atrações, tais como a audiência dos episódios, as fichas técnicas do elenco e a biografia dos personagens, a Wikia auxilia na compreensão das tramas.

A conversação em rede ${ }^{3}$ também possibilitou a formação de conexões, aparentemente, diretas entre os fãs e os roteiristas dos programas. Como ressalta Bennett:

1 Aquele que possui uma ligação intelectual e afetiva com algo.

2 Disponível em: <https://bit.ly/20RztS6>. Acesso em: 22 jan. 2018.

3 A conversação em rede "surge dos milhares de atores interconectados que dividem, negociam e constroem contextos coletivos de interação, trocam e difundem informações, criam laços e estabelecem redes sociais" (RECUERO, 2014, p. 19). 
antes os fãs só podiam estabelecer contato com os produtores/roteiristas através de cartas, que muitas vezes eram interceptadas pelos canais, com as redes sociais como o Twitter, o Facebook e o Instagram essa comunicação ficou mais direta e imediata. ${ }^{4}$ (Ibid., p. 8, tradução nossa)

Além de trocar informações e tirar dúvidas sobre o universo ficcional, a ampliação do diálogo estabelecido pelos fãs pode alterar o curso das decisões tomadas pelas emissoras. Como, por exemplo, nas ações organizadas pelos fandoms $s^{5}$ durante o período de renovação das temporadas das narrativas ficcionais seriadas estadunidenses.

Diante dos baixos índices de audiência e da ameaça de cancelamento após a exibição da segunda temporada, os fãs de The Leftovers (2014-2017, HBO) decidiram mobilizar-se para chamar a atenção do canal HBO. Caracterizados como personagens da história, os membros do Guilty Remnant, ${ }^{6}$ e segurando placas com a palavra "Renew" um grupo de fãs se reuniu na porta da sede da emissora em Nova York, nos Estados Unidos, para pedir a renovação do programa. O protesto rapidamente foi noticiado pela imprensa e divulgado pelo público nas redes sociais. Para demonstrar apoio ao fandom, fãs de várias partes do mundo publicaram mensagens usando a hashtag \#renewtheleftovers. Após quatro ${ }^{8}$ dias de protesto, a $\mathrm{HBO}$ anunciou a renovação de The Leftovers para a sua terceira e última temporada. Apesar de a emissora não ter declarado oficialmente o que a levou a produzir novos episódios, muitos ${ }^{9}$ sites especializados atribuíram a decisão à ação organizada pelos fãs em Nova York.

Segundo Jenkins (2012), Hirsjärvi (2013), Herrero-Diz et al. (2017) e Borges et al. (2017), essas práticas da cultura de fãs dialogam diretamente com o conceito de competência midiática. "Assistir à televisão como fã envolve níveis de atenção diversos e convoca competências diversas de espectador, diferente de quando se assiste ao mesmo conteúdo de forma causal" (JENKINS, 2015, p 73). Como ressalta Booth, em entrevista a Grandío, o público ávido possui um entendimento crítico não só dos universos ficcionais, mas das plataformas digitais. Isto é, os fãs sempre abraçam as novas tecnologias e buscam

4 No original: "in previous years, fans could send messages to the object of fandom via a letter in the post, which may have been filtered by management, the possibility for a direct and more immediate connection has arisen, through social media platforms such as Twitter, Facebook and Instagram”.

5 Fandom se refere a um conjunto de fãs, em sua tradução literal o termo faz referência a algo como "reino dos fãs", pela presença do sufixo “-dom”, proveniente de kingdom (reino).

6 Na série, o Guilty Remnant é um grupo que acredita que a Partida foi um Arrebatamento Bíblico. Um dos seus propósitos é fazer com que os 'deixados para trás' não se esqueçam do que aconteceu. Disponível em http://the-leftovers.wikia.com/wiki/Guilty_Remnant. Acesso em: 22 jan. 2018.

7 Renovem em português.

8 O protesto começou no dia 7 de dezembro de 2015 e o anúncio da renovação aconteceu no dia 11 de dezembro.

9 Tais quais: Hollywood Reporter, TV Line, TV Guide, Deadline, Seriable e Digital Trends. 
compreender as potencialidades da arquitetura informacional das redes sociais para propagarem e ressignificarem seus conteúdos (BOOTH apud GRANDÍO, 2016, p. 148-151).

De acordo com Ferrés e Piscitelli (2015, p. 3), a competência é "geralmente entendida como uma combinação de conhecimentos, habilidades e atitudes consideradas necessárias para um contexto determinado". Nesse sentido, a competência midiática contribui para a autonomia e o desenvolvimento da capacidade crítica dos cidadãos, estando presente tanto na maneira como consumimos os conteúdos midiáticos, quanto no modo como os produzimos.

A partir desse aporte teórico, este artigo tem como objetivo analisar as dimensões da competência midiática que estão em operação nos protestos organizados, nos Estados Unidos, pelos fãs da série The Handmaid's Tale (2017-atual, Hulu). Para a reflexão desta questão iremos adotar a metodologia proposta por Ferrés e Piscitelli (Ibid.) para avaliar e promover o desenvolvimento da competência midiática na cultura participativa. Segundo os autores, as revoluções tecnológicas e neurobiológicas apontam a necessidade de potencializar a dimensão participativa dos processos de comunicação. Neste sentido, a participação não se refere apenas aos modos como um indivíduo se expressa criativamente, pois a análise das mensagens também influi no modo como elas são criadas. Desta forma, a competência midiática é formada a partir de uma abordagem ativa e dialógica, levando em consideração a participação do interlocutor nos processos de seleção, interpretação, aceitação ou rejeição, análise crítica e transmissão, entre outros, que estimulam e sustentam a sua produção criativa.

\section{O protagonismo feminino nas narrativas ficcionais seriadas}

De acordo com Lotz (2006), até a década de 1980 a mulher era representada nas narrativas ficcionais seriadas estadunidenses a partir de uma perspectiva sexista. Apesar de evidenciarem, pontualmente, as habilidades intelectuais da mulher, as personagens de tramas como, por exemplo, Police Woman (1974-1978, CBS), Get Christie Love (1974-1975, ABC), Charlie's Angels (1976-1981, ABC) e Wonder Woman (19751979, ABC), eram subordinadas aos homens e sexualmente objetificadas (SIGILIANO; CAVALCANTI; BORGES, 2017).

Produzida pelo canal estadunidense CBS, a série Cagney e Lacey (1981-1988, CBS), protagonizada pelas atrizes Sharon Gless e Tyne Daly, representou uma quebra de paradigma (LOTZ, 2006). A trama, que se estendeu por sete temporadas, tinha como arco narrativo central a rotina de investigação das detetives Christine Cagney (Sharon Gless) e Beth Lacey (Tyne Daly). Como pontua Lotz (Ibid.), além de inteligentes e habilidosas, as personagens 
levantavam reflexões sobre a sororidade. O retorno positivo da crítica e da audiência fez com que outros canais dos Estados Unidos investissem em séries com mulheres independentes, bem-sucedidas profissionalmente e empoderadas, como nas séries Buffy The Vampire Slayer (1997-2003, The WB), La Femme Nikita (1997-2001, CTV), Felicity (1998-2002, WB), Sex and the City (1998-2004, HBO), Providence (1999-2002, NBC), entre outras.

Porém, é importante ressaltar que essa mudança no modo de representação da mulher nas narrativas ficcionais seriadas estadunidenses não abrange todas as produções exibidas entre os anos 1980 e 1990. Como afirmam Lotz (Ibid.) e Dow (2010), muitas séries, apesar de serem protagonizadas por personagens femininas, tinham como arco narrativo central a busca, mesmo que indireta, pela aprovação de uma figura masculina.

A partir dos anos 2000, as séries passam a explorar, de forma mais pontual, o protagonismo feminino (MITELL, 2010; MARTIN, 2014). Segundo Martin (2014, p. 22), as personagens deixam de ser "um obstáculo ou um estímulo ao progresso existencial do herói masculino". As séries Weeds (2005-2012, Showtime), Damages (2007-2012, FX), Homeland (2011-presente, Showtime), Halt and Catch Fire (2014-2017, AMC) e Big Little Lies (2017- atual, HBO), por exemplo, são norteadas pelos pontos destacados pelo autor.

O mesmo acontece com as tramas de Shonda Rhimes. Criadora e produtora das séries Grey's Anatomy (2005-presente, ABC), Scandal (2012-presente, ABC), How to Get Away with Murder (2014-presente, ABC) e The Catch (2016-2017, ABC), a roteirista desenvolve personagens fortes, complexas e inteligentes, que se distanciam do sexismo e da objetificação presentes nos programas das décadas de 1970 e 1980. Como destaca Levine (2013, p. 142-143, tradução nossa),

As personagens femininas de Grey's se distanciam da perfeição, elas têm falhas, têm problemas na vida pessoal e profissional, e muitas vezes são infelizes. Mas em nenhum momento suas escolhas profissionais são colocadas em questão, representando um erro. Pelo contrário, a profissão é aquilo que as define, as deixa orgulhosas, o que também acaba se distanciando do formato soap opera, a escolha por uma carreira, por uma profissão não entra em conflito com a vida pessoal. ${ }^{10}$

A ascensão do protagonismo feminino nas narrativas ficcionais seriadas não se limita ao âmbito televisivo, a representação de mulheres que se opõem à lógica do

10 No original: "The female characters of Grey's are flawed, beset with troubles, and frequently unhappy, but their work as surgeons is never represented as a mistake or even as a particularly costly choice. It defines them and makes them proud, another nod to daytime soap opera, with its accomplished career women who suffer unrelated personal travails".

$110 \frac{\text { Comunicação \& Inovação, PPGCOM/USCS }}{\text { v. 19, n. } 40 \text { (106-122) maio-ago } 2018}$ 
patriarcado também está presente nas produções originais dos serviços de conteúdo on demand. Plataformas como a Netflix, a Amazon Prime Video e o Hulu estrearam nos últimos anos séries que, além de serem protagonizadas por mulheres, abordam questões ligadas à misoginia. As séries Orange Is the New Black (2013-presente, Netflix), The Fall (2013-2015, BBC Two/ Netflix), The Marvelous Mrs. Maisel (2017-atual, Amazon Prime Video) e I Love Dick (2016, Hulu), por exemplo, são constantemente usadas na discussão de temas relacionados ao feminismo. ${ }^{11}$ Entretanto, é importante destacar que, apesar da nítida mudança na ficção seriada, ainda estamos distantes de um cenário que reflita, de fato, a paridade entre personagens femininos e masculinos.

Produzida pelo Hulu, The Handmaid's Tale (2017- atual) é baseada no romance ${ }^{12}$ homônimo de Margaret Atwood, lançado em 1985. A trama é ambientada na distopia de Gileade, uma sociedade totalitária que, anteriormente, foi parte dos Estados Unidos. Após a queda drástica na taxa de natalidade, Gilead passa a ser governada por um fundamentalismo religioso que trata as mulheres como propriedade do Estado. As poucas mulheres férteis são forçadas à servidão sexual como uma última tentativa de repovoar o mundo. A série é protagonizada por Elisabeth Moss, a atriz interpreta Offred, uma aia que vive entre comandantes e suas mulheres cruéis, e que busca sobreviver e encontrar a filha.

O viés político de The Handmaid's Tale chamou imediatamente a atenção do público, poucas semanas após a sua estreia, a trama já tinha se tornado um dos grandes símbolos do feminismo, no âmbito do audiovisual. Vestidas como as aias da atração do Hulu, os fãs da série têm se mobilizado pelos Estados Unidos em prol da luta pelos direitos das mulheres. Como ressalta Vagianos (2017),

Mulheres com longas túnicas vermelhas e chapéus brancos - em referência à personagem Offred, da distopia de Margaret Atwood O Conto da Aia (The Handmaid's Tale) - se tornaram uma visão cada vez mais comum ao longo dos últimos meses. Do Texas à Califórnia e até a capital Washington, mulheres têm usado os trajes de aia para protestar contra retrocessos nos direitos reprodutivos das mulheres e sistema de saúde da gestão Trump.

Porém, o ativismo não se restringe apenas às narrativas ficcionais seriadas que exploram, de algum modo, questões relacionadas ao feminismo. De acordo com Brough e Shresthova (2012) e Bennett (2014), a resistência e a mobilização criativa, cultural e social estão imbricadas com a cultura de fãs em sua totalidade.

11 Mais conteúdo sobre o assunto disponível em: $<$ https://bit.ly/2IzwMD8 $>$; $<$ https://theatln.tc/2rUz2xH $>$; $<$ https://usat.ly/2GuLZUp>. Acesso em: 25 jan. 2018.

12 No Brasil publicado como O Conto da Aia. 


\section{A cultura de fãs e o ativismo}

Van Zoonen (2004, p. 46) afirma que, nas práticas da cultura de fãs, é possível identificar o que há de mais fundamental para a democracia política: a informação, a discussão e o ativismo. Seja através das discussões, das mobilizações ou do engajamento, os fãs estabelecem uma relação muito próxima com questões que envolvem a participação cívica e cidadã (BROUGH; SHRESTHOVA, 2012). Como pontua Jenkins (2008, p. 285-321), a ampliação do ativismo político está acontecendo, em parte, graças ao modo como o público ávido se engaja criativamente e criticamente na cultura popular.

De acordo com Amaral, Souza e Monteiro (2015), a mobilização dos fãs pode ser associada a diversas formas de resistência no âmbito criativo e cultural. Nesse sentido, o ativismo engloba um amplo universo de práticas como, por exemplo, campanhas reivindicando a permanência de um programa no ar, discussões sobre a representação de minorias e a promoção de questões sociais na trama, o engajamento em torno da liberação de algum conteúdo específico, etc. (Ibid.).

Brough e Shresthova (2012) afirmam que o ativismo de fãs apresenta quatro pontos centrais. São eles: as interconexões entre a participação política e cultural; a tensão entre a participação e a resistência; o papel do afeto/gosto em mobilizar a participação cívica; o impacto das mobilizações no perfil do fandom. As questões ressaltadas pelas autoras podem ser observadas em distintas práticas da cultura de fãs. Fundada em 2015, a entidade filantrópica The Harry Potter Alliance ${ }^{13}$ engaja fãs do mundo inteiro em prol de campanhas sociais. As ações, organizadas pelos leitores da franquia de J. K. Rowling, já chegaram a arrecadar mais de 41 mil livros para as pessoas que não tem acesso à literatura, e cerca de 123 mil dólares para as vítimas do terremoto no Haiti.

Considerada por Rose (2011) e Jenkins, Green e Ford (2014) um dos casos mais tangíveis sobre o poder de influência dos fãs nas decisões das emissoras estadunidenses, a renovação de Chuck (2007-2012, NBC) só foi possível por conta de mobilização do fandom da série. Conforme explica Rose (2011), em 2011 o programa estava prestes a ser retirado do ar pela NBC, entretanto os telespectadores ávidos criaram uma campanha para chamar a atenção das empresas que patrocinavam a atração. Liderados pelo site We Give $a C h u c k^{14}$, o objetivo da ação era mostrar ao canal que a métrica de audiência não representava o número real de telespectadores do programa. Para isso, durante os intervalos comerciais de Chuck, os fãs enviavam tuítes para os perfis dos anunciantes comentando sobre o produto e demonstrando que eles poderiam dar retorno às marcas. Entretanto,

13 Disponível em: <https://bit.ly/2ayXj37>. Acesso em: 26 jan. 2018.

14 Disponível em: <https://bit.ly/2ITqhyz >. Acesso em: 26 jan. 2018.

$112 \frac{\text { Comunicação \& Inovação, PPGCOM/USCS }}{\text { v. 19, n. } 40 \text { (106-122) maio-ago } 2018}$ 
mesmo com a repercussão nas redes sociais e a divulgação na imprensa especializada (PONIEWOZIC, 2009), a NBC continuava irredutível na sua decisão. A um passo de perder sua série favorita, os fãs tiveram que mudar sua estratégia. Através do site We Give a Chuck, eles pediram que todos os telespectadores do programa fossem ao Subway, o patrocinador com a maior cota publicitária ${ }^{15}$ da atração, todas as segundas-feiras e comprassem um sanduíche. A aceitação do fandom foi tamanha que a empresa teve que contratar funcionários para suprir a demanda (ROSE, 2011, p. 196). O resultado não poderia ser outro, a NBC voltou atrás e decidiu produzir novos episódios de Chuck.

As redes sociais também exercem um papel fundamental no ativismo do público ávido, os grupos do Facebook Aussie X-Files Fans ${ }^{16}$ e heART, ${ }^{17}$ mantidos pelos fãs da série The $X$-Files (1993-2002, ${ }^{18}$ Fox), por exemplo, organizam leilões com itens da trama para projetos educacionais na África do Sul (JONES, 2011). Cada campanha feita pelos fãs do programa arrecada, em média, 20 mil euros. Dessa forma, a ligação afetiva e intelectual que os fãs têm com os programas vai além dos universos ficcionais e passa a mobilizar ações sociopolíticas.

\section{O ativismo dos fãs de The Handmaid's Tale}

A competência midiática envolve o domínio de conhecimentos, habilidades e atitudes dos indivíduos em relação às mensagens midiáticas. Para operacionalizar metodologicamente o uso do conceito, Ferrés e Piscitelli (2015, p. 8-14) definiram seis dimensões a partir das quais os indicadores são elaborados. Por sua vez, estes se relacionam tanto ao âmbito de análise, isto é, à forma como as pessoas recebem e interagem com as mensagens, quanto ao âmbito de expressão, que se refere ao modo como as mensagens são produzidas pelas pessoas. É importante ressaltar que os pontos teorizados pelos autores estão inter-relacionados, ou seja, esta separação é feita para que possamos analisar didaticamente cada uma delas. São elas: linguagem, ideologia e valores, estética, tecnologia, processos de interação e de produção e difusão.

Neste artigo iremos focar na dimensão da ideologia e valores, segundo Ferrés e Piscitelli (Ibid., p. 13-14), esta dimensão envolve a capacidade dos interagentes de repercutir de forma crítica o modo como as representações midiáticas estruturam nossa percepção da realidade; a habilidade de detectar, contrastar, buscar e avaliar as intenções e interesses presentes nos conteúdos; a capacidade de analisar criticamente as produções, identificando estereótipos; bem como gerir as próprias emoções, identificando o potencial mecanismo de

15 Estimada em 34 milhões de dólares (ROSE, 2011, p. 194).

16 Disponível em: <https://bit.ly/2IxSFmo>. Acesso em: 27 jan. 2018.

17 Disponível em: <https://bit.ly/2IPog6x>. Acesso em: 27 jan. 2018.

18 Depois de 14 anos de hiato, a décima e a décima primeira temporada foram exibidas em 2016 e 2018. 
manipulação das telas. No âmbito da expressão está relacionada com a capacidade de usar as novas mídias para se comprometer como cidadão, além de elaborar e modificar produtos para questionar valores ou estereótipos presentes nas produções midiáticas.

A partir da metodologia proposta por Ferrés e Piscitelli (Ibid.) iremos analisar três protestos realizados pelos fãs de The Handmaid's Tale. As manifestações foram organizadas pelo site The Handmaid's Coalition nos meses de março, maio e junho de 2017, nos Estados Unidos (FERRERO, 2017; 'HANDMAID’S..., 2017; HAUSER, 2017).

Criado em 2017, o site The Handmaid's Coalition ${ }^{19}$ tem como objetivo instruir fãs do mundo todo na realização de mobilizações em prol dos direitos da mulher e da igualdade de gênero. Conforme explica a fã e fundadora da organização, Emily Morgan,

Nosso trabalho visa um mundo em que todos, independentemente do sexo, raça, religião, orientação sexual ou identidade de gênero, tenham voz igual nas discussões e decisões políticas nos níveis local, estadual e federal. Nós nos esforçamos para criar um espaço online onde os membros podem encontrar apoio e oportunidade para compartilharem suas experiências. ${ }^{20}$ (MORGAN, 2017, tradução nossa)

Nos últimos meses, o site recebeu mais dois mil formulários de voluntários de vários países como Estados Unidos, Canadá e Espanha. Com o slogan "Lutar para evitar que a ficção se torne realidade", ${ }^{21}$ o The Handmaid's Coalition mistura o universo ficcional da série do Hulu com a contemporaneidade, mostrando que a história distópica criada por Margaret Atwood é mais verossímil do que aparenta.

O site apresenta informações como, por exemplo, o contexto da série The Handmaid's Tale, o perfil dos fãs que administram a plataforma, as notícias sobre projetos de lei relacionados às minorias e os direitos da mulher, etc. Porém, o ponto central do The Handmaid's Coalition são as instruções que o site disponibiliza para os fãs que pretendem organizar um protesto em suas cidades. O formulário de cadastro dos voluntários que querem ajudar a causa de alguma maneira, seja propondo ações de engajamento nas redes sociais, traduzindo os materiais da organização ou participando efetivamente dos protestos, inclui informações que compreendem desde dados básicos (nome, e-mail, cidade, etc.) até uma seção onde o fã pode compartilhar suas experiências. Os relatos abrangem

19 Disponível em: <https://bit.ly/2wTop4d $>$. Acesso em: 28 jan. 2018.

20 No original: "We do this to work toward an world in which everyone, regardless of sex, race, religion, sexual orientation, or gender identity, has an equal voice in the political discussions and decisions at local, state, and federal levels. We strive to create a place online where members can find support and an opportunity to share their experiences".

21 Fight to keep fiction from becoming reality, no inglês.

$114 \frac{\text { Comunicação \& Inovação, PPGCOM/USCS }}{\text { v. 19, n. } 40 \text { (106-122) maio-ago } 2018}$ 
denúncias de assédio sexual, depoimentos sobre relacionamentos abusivos e descrições sobre projetos de lei, relacionados às questões sociais defendidas pela organização, que estão sendo propostos pelos governantes de vários países do mundo. Nesse sentido, o site ajuda os fãs a compreenderem criticamente o universo ficcional de The Handmaid's Tale, estabelecendo uma correlação entre a ficção e a realidade. Usando os temas abordados nos arcos narrativos da trama para se engajarem politicamente.

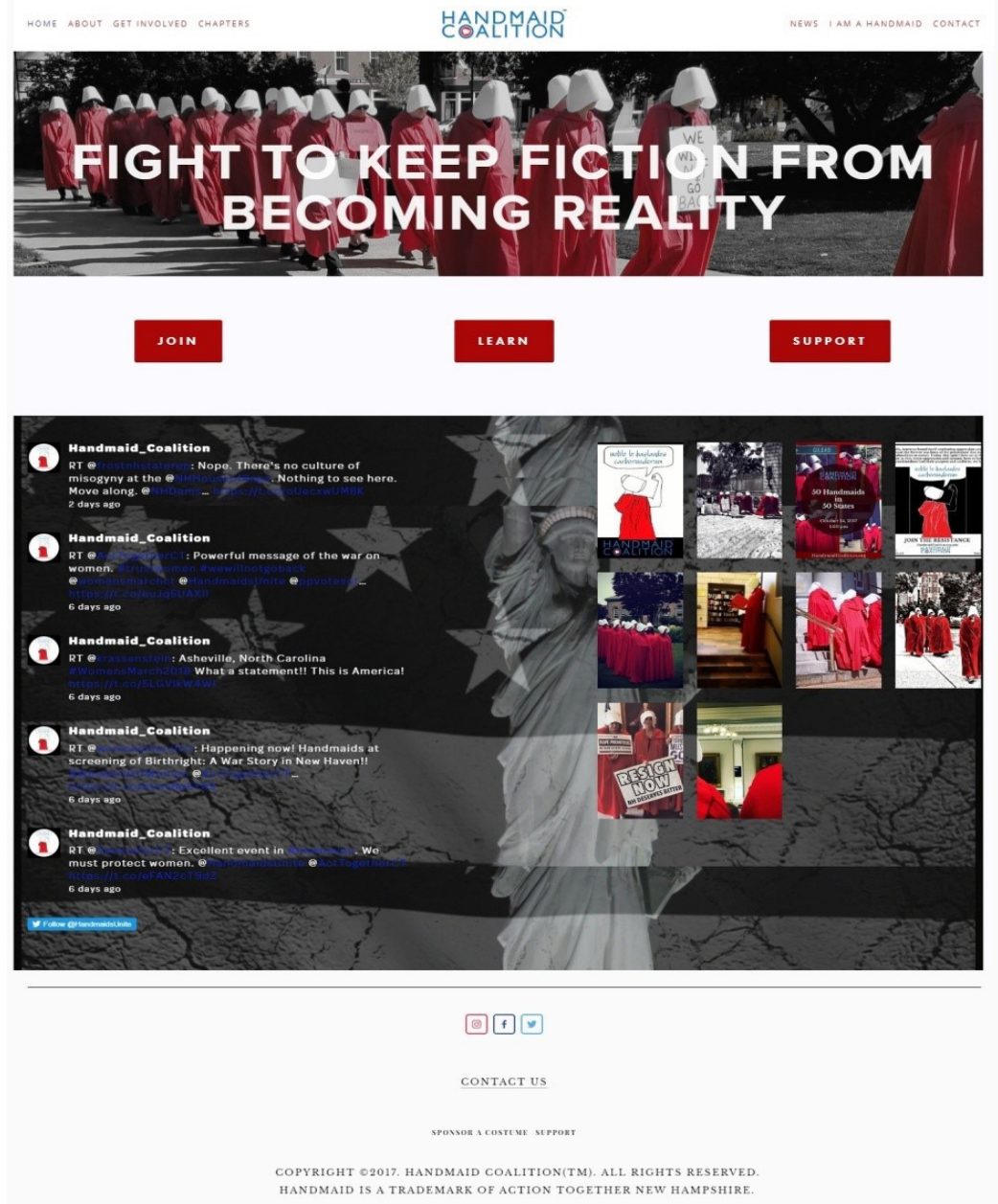

Figura 1. Captura de tela do site The Handmaid's Coalition

Fonte: The Handmaid's Coalition. ${ }^{22}$

Disponibilizado para download em formato de arquivo PDF, o The Handmaid's Guide $^{23}$ ensina os fãs o passo a passo, com medidas e moldes, da confecção das roupas usadas nas manifestações (THE HANDMAID'S COALITION, 2018).

22 Disponível em: $<$ https://bit.ly/2wTop4d $>$. Acesso em: 28 jan. 2018.

23 Disponível em: <https://bit.ly/2rUG5q5>. Acesso em: 28 jan. 2018. 

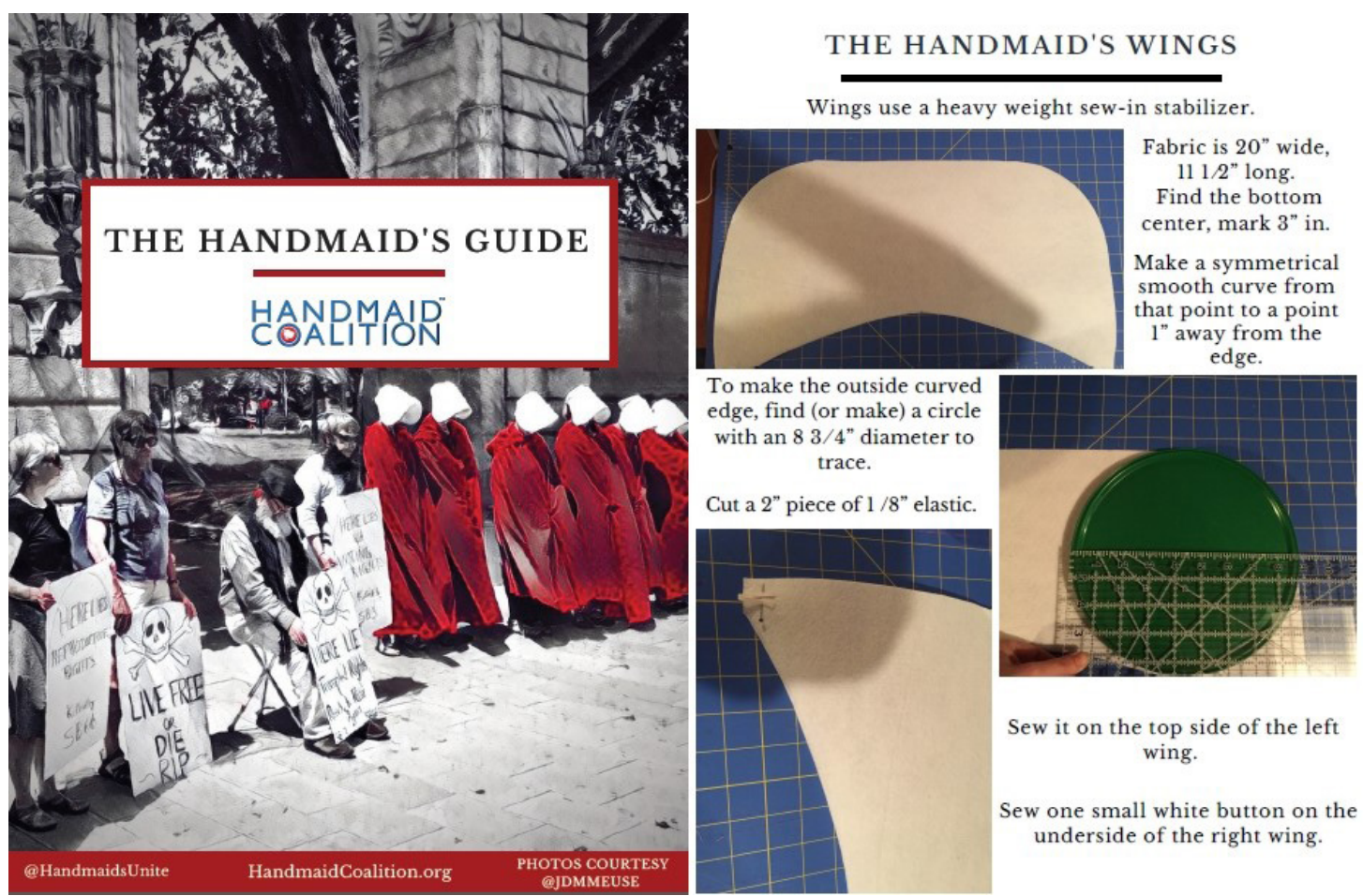

Figura 2. O The Handmaid's Guide oferece várias informações aos fãs da série

Fonte: The Handmaid's Coalition. ${ }^{24}$

Como iremos discutir mais adiante, os protestos organizados pelo público ávido da série do Hulu seguem um padrão, além de se manterem em silêncio, as ativistas se vestem como a protagonista da trama, interpretada pela atriz Elisabeth Moss. No universo ficcional de The Handmaid's Tale as roupas fazem referência à República de Gilead ${ }^{25}$, o lugar fictício onde se passa a história. $\mathrm{O}$ vermelho usado pelas aias representa a fertilidade das mulheres, associando o tom escarlate com a menstruação. Como explica a figurinista da série Ane Crabtree,

O vermelho é a cor da regra, do útero, das mulheres desenfreadas e pecadoras. Historicamente, o vermelho é visto como símbolo de poder, usado por reis e líderes religiosos, mas o único poder que as aias têm é a capacidade de dar descendência. ${ }^{26}$ (THE SYMBOLISM..., 2017, tradução nossa)

Em contrapartida, o azul turquesa presente nas vestes das esposas dos comandantes faz alusão à Virgem Maria, simbolizando a pureza e a santidade. Para as fãs que

24 Disponível em: <https://bit.ly/2wTop4d >. Acesso em: 28 jan. 2018.

25 Disponível em: $<$ https://bit.ly/2ICgFc8>. Acesso em: 28 jan. 2018.

26 No original: "The color red indicates the Handmaids' fertility, echoing the color of menstrual blood. Historically, red has been seen as a symbol of power, worn by kings and religious leaders, yet the Handmaids' only power is their presumed ability to bear children".

$116 \frac{\text { Comunicação \& Inovação, PPGCOM/USCS }}{\text { v. 19, n. } 40 \text { (106-122) maio-ago } 2018}$ 
integram o The Handmaid's Coalition, além de significarem a repressão do patriarcado, as roupas das aias se tornaram um emblema da solidariedade e da colaboração das mulheres na luta pela igualdade de gênero (FERRERO, 2017).

Emily Morgan (THE HANDMAID'S COALITION, 2017), afirma que além do aspecto simbólico, a roupa adotada pelas fãs durante os protestos é funcional. Como explica a fundadora da organização, o chapéu branco ajuda a proteger as identidades das manifestantes e a uniformidade dos trajes reforça as causas pelas quais o fandom luta.

Desde a criação do The Handmaid's Coalition, os protestos dos fãs da série do Hulu têm crescido de maneira significativa. Segundo as reportagens do El País (FERRERO, 2017), BBC ('HANDMAID'S..., 2017) e CNN (2017), nos últimos meses foram realizadas manifestações não só nos Estados Unidos, mas na Espanha, Alemanha, Polônia e Portugal. Além de se vestirem como as aias da série, os fãs adotam uma postura específica durante as ações. Como descreve a repórter do New York Times, Christine Hauser, "Silenciosas e com as cabeças curvadas, os ativistas com roupas vermelhas e chapéus brancos aparecem em manifestações contra a discriminação de gênero e a violação dos direitos civis ${ }^{27}$ (HAUSER, 2017, tradução nossa). No The Handmaid's Guide, as organizadoras afirmam que silêncio faz alusão aos abusos e repressões sofridas pelas mulheres. Ao olharem as aias protestando, o público faz, mesmo que involuntariamente, uma correlação entre as causas de Offred (Elisabeth Moss) na trama e a atual conjuntura política e social, propiciando o entendimento crítico do diálogo entre ficção e a realidade.

Neste artigo, nos debruçaremos sobre três protestos realizados nos meses de março, maio e junho de 2017, nos estados do Texas, Washington e Nova Hampshire, nos Estados Unidos.

Em março de 2017, os corredores do Capitólio do Texas foram tomados pelos fãs de The Handmaid's Tale. As mulheres protestavam contra um projeto de lei antiaborto proposto pelo legislativo do estado. Apesar de estarem completamente em silêncio, ${ }^{28}$ as manifestantes carregavam cartazes que mostravam as restrições do aborto, no Texas, embargadas desde que a Suprema Corte, no caso Roe versus Wade, legalizou o procedimento em todo o país. Nesse sentido, os fãs da trama do Hulu usavam o espaço para chamar a atenção para o processo histórico conjuntural dos direitos reprodutivos nos Estados Unidos, e como eles são fundamentais para a saúde integral das mulheres.

27 No original: "Silent, heads bowed, the activists in crimson robes and white bonnets have been appearing at demonstrations against gender discrimination and the infringement of civil rights".

28 Vídeo do protesto disponível em: <https://bit.ly/2rYZxmn>. Acesso em: 29 jan. 2018. 



Figura 3. Em sentido horário, vemos os protestos no Texas, Washington e Nova Hampshire, respectivamente. Na parte debaixo da imagem vemos as cenas da série The Handmaid's Tale

Fonte: The Handmaid's Coalition. ${ }^{29}$

Lideradas por grupo local de voluntários do The Handmaid's Coalition, as fãs da atração do Hulu também se engajaram contra o machismo. Em maio de 2017, um grupo de aias protestaram na porta da State House de Nova Hampshire, pedindo o afastamento do político Robert Fisher, do partido Republicano. As reivindicações foram em decorrência da participação ${ }^{30}$ de Fisher em um fórum do Reddit chamado The Red Pill, ${ }^{31}$ que é conhecido por seu conteúdo extremamente misógino. As manifestantes levaram cartazes com frases mostrando o sexismo presente nas postagens dos membros do fórum.

Por fim, em junho de 2017, para protestar contra o sistema de saúde da gestão de Donald Trump, as fãs de série se reuniram em frente ao Capitólio, em Washington, DC. Enquanto o Senado debatia sobre a possível interrupção do Planned Parenthood, as manifestantes, vestidas como as aias de The Handmaid's Tale, mostravam faixas alertando que caso o projeto de lei fosse aprovado, milhares de mulheres ficariam sem acesso a atendimento médico. Segundo a voluntária do The Handmaid's Coalition, Elena Lipsiea, a interconexão estabelecida entre o universo criado por Margaret Atwood e a atual situação política dos Estados Unidos ajuda as pessoas a compreenderem a importância

29 Disponível em: < https://bit.ly/2wTop4d >. Acesso em: 28 jan. 2018.

30 Disponível em: <https://bit.ly/2x38IY4>. Acesso em: 30 jan. 2018.

31 O fórum existe desde 2012 e possui 195 mil membros.

118 Comunicação \& Inovação, PPGCOM/USCS 
do engajamento em movimentos sociais. "Vestir-se como uma aia passa uma mensagem clara à nossa administração e ao Senado sobre o quanto estamos atentas às decisões tomadas no Capitólio e de que maneira esse projeto pode afetar radicalmente nossas vidas", ${ }^{32}$ explica a fã (BONDARENKO, 2017, tradução nossa).

Os protestos organizados pelos fãs de The Handmaid's Tale em prol da luta pelos direitos das mulheres e pela igualdade de gênero dialogam diretamente com a dimensão da ideologia e valores proposta por Ferrés e Piscitelli (2015). A partir dos arcos narrativos explorados na trama, os fãs estabelecem um paralelo com a contemporaneidade. Como pudemos observar, o universo ficcional do programa estimulou os telespectadores ávidos a se aprofundarem nas questões sociais retratadas na história. Seja através de relatos sobre abusos, da investigação de projetos de lei que vão de encontro aos direitos das mulheres, ou das manifestações, os fãs passam a se comprometerem como cidadãos críticos.

\section{Considerações Finais}

O ativismo dos fãs de The Handmaid's Tale ressalta a relevância da leitura crítica e criativa de um conteúdo midiático. Nesse sentido, os temas abordados nos arcos narrativos da série estimulam a reflexão dos telespectadores ávidos. Os fãs, mesmo que indiretamente, traçam um paralelo entre o universo ficcional da série do Hulu e a contemporaneidade, refletindo sobre os direitos das mulheres e a igualdade de gênero. Essa ponte estabelecida entre a ficção e a realidade propicia a emersão de mobilizações em prol das questões sociopolíticas.

$\mathrm{O}$ site The Handmaid's Coalition também reforça o comprometimento cidadão dos fãs. Além de ajudar na organização dos protestos, promover a troca de informações e experiências de vida, a plataforma propicia a instrução dos telespectadores ávidos. Todo o protesto é norteado por um constante acompanhamento de projetos de lei e de medidas governamentais que possam ferir de algum modo os direitos das mulheres. Nesse contexto, o ativismo dos fãs não se resume a uma simples transposição da sociedade distópica criada por Margaret Atwood para a atual conjuntura política, mas a interpretação crítica da causa, envolvendo pesquisas sobre o tema, seus objetivos e consequências.

Dessa forma, a dimensão da ideologia e valores proposta por Ferrés e Piscitelli (Ibid.) está presente no modo como os fãs se relacionam com The Handmaid's Tale. A trama vai além do serviço de conteúdo on demand e serve de ponto de partida para que as discussões sobre as questões culturais, sociais e políticas relacionadas aos direitos das mulheres sejam exploradas pelos fãs de diversas formas.

32 No original: "Dressing up as a handmaid gives a clear message to our administration and the Senate about how seriously we take their decisions and how radically it can affect our lives". 


\section{Referências}

AMARAL, A.; SOUZA, R. V.; MONTEIRO, C. De Westeros no \#vemprarua à shippagem do beijo gay na TV brasileira. Ativismo de fãs: conceitos, resistências e práticas na cultura digital. Galáxia, São Paulo, n. 29, p. 141-154, jun. 2015. Disponível em: <https://bit.ly/2k7VwIi>. Acesso em: 31 jan. 2018.

BENNETT, L. Tracing textual poachers: reflections on the development of fan studies and digital fandom. Journal of Fandom Studies, Oxford, v. 2, n. 1, p. 5-20, 2014. Disponível em: <https://bit.ly/2Gywpfh>. Acesso em: 31 jan. 2018.

BONDARENKO, V. Planned parenthood staged a 'Handmaid's Tale': inspired demonstration on Capitol Hill to protest the healthcare bill. Business Insider, New York, 27 jun. 2017. Disponível em: $<$ https://read.bi/2KyEePK>. Acesso em: 31 jan. 2018.

BOOTH, P. Digital fandom: new media studies. New York: Peter Lang, 2010.

BORGES, G. et al. Fãs de Liberdade, Liberdade: curadoria e remixagem na social TV. In: Vassallo de Lopes, M. I. (Ed.). Por uma teoria de fãs da ficção televisiva brasileira II: práticas de fãs no ambiente da cultura participativa. Porto Alegre: Sulina, 2017. p. 93-135.

BROUGH, M.; SHRESTHOVA, S. Fandom meets activism: rethinking civic and political participation. Transformative Works and Cultures, New York, v. 10, 2012. Disponível em: <https://bit.ly/2KBkxa1>. Acesso em: 31 jan. 2018.

DOW, B. Ally McBeal, lifestyle feminism, and the politics of personal happiness. The Comunication Review, Abingdon, v. 5, n. 4, p. 259-264, set. 2010. Disponível em: <https://bit.ly/2IseE2a>. Acesso em: 31 jan. 2018.

FERRERO, C. No mundo pós-Trump, a revolução feminista se tingiu de vermelho. El País, São Paulo, 15 jul. 2017. Disponível em: <https://bit.ly/2GyS8Pu>. Acesso em: 31 jan. 2018.

FERRÉS, J; PISCITELLI, A. Competência midiática: proposta articulada de dimensões e indicadores. Lumina, Juiz de Fora, v. 9, n, 1, p. 1-16, jan. 2015. Disponível em: <https://bit.ly/2rWbUgE>. Acesso em: 31 jan. 2018.

GRANDÍO, M. Adictos a las series: 50 años de lecciones de los fanes. Barcelona: UOC, 2016.

'HANDMAID'S tale' protest at US Ohio abortion bill. $B B C$, Londres, 13 jun. 2017. Disponível em: $<$ https://bbc.in/>. Acesso: 31 jan. 2018.

HAUSER, C. A Handmaid's Tale of Protest. The New York Times, 30 jun. 2017. Disponível em: $<$ https://nyti.ms/2IvFBOh>. Acesso em: 31 jan. 2018.

HERRERO-DIZ, P. et al. Estudio de las competencias digitales en el espectador fan español. Palabra Clave, Bogotá, v. 20, n. 4, p,17-947, dez. 2017. Disponível em: <https://bit.ly/2uMbGPz>. Acesso em: 31 jan. 2018.

HIRSJÄRVI, I. Alfabetización mediática, fandom y culturas participativas. Un desafío global. Anàlisi Monogràfic, Barcelona, n. 48, p. 37-48, set. 2013. Disponível em: <https://bit.ly/2IRWcPP>. Acesso em: 31 jan. 2018. 
JENKINS, H. Cultura da convergência. 2. ed. São Paulo: Aleph, 2008. Invasores do texto: fãs e cultura participativa. Rio de Janeiro: Marsupial, 2015. Lendo criticamente e lendo criativamente. Matrizes, São Paulo, v. 9, n. 1, p. 11-24, jul. 2012. Disponível em: <https://bit.ly/2EkqAMr>. Acesso em: 31 jan. 2018.

JENKINS, H.; GREEN, J.; FORD, S. Cultura da conexão: criando valor e significado por meio da mídia propagável. São Paulo: Aleph, 2014.

JONES, B. Being of service: X-Files fans and social engagement. Transformative Works and Cultures, Tulane, v. 10, p.1-1, mar. 2011. Disponível em: <https://bit.ly/2LwqXaD>. Acesso em: 7 jun. 2018.

LEVINE, E. Grey's Anatomy: Feminism. In: THOMPSON, E.; MITTELL, J. (Eds.). How to watch television. New York: New York University Press, 2013. p. 139-147.

LOTZ, A. Redesigning women: television after the network era. Chicago: University of Illinois Press, 2006.

MARTIN, B. Homens dificeis: os bastidores do processo criativo de Breaking Bad, Família Soprano, Mad Men e outras séries revolucionárias. São Paulo: Aleph, 2014.

MITTELL, J. Television and American culture. New York: Oxford University Press, 2010.

MORGAN, E. Mission. The Handmaid's Coalition, 11 dez. 2017. Disponível em: <https://bit.ly/2M1Mg5b>. Acesso em: 7 jun. 2018.

PEARSON, R. Fandom in the digital era. Popular Communication: The International Journal of Media and Culture, Abingdon, v. 8, n. 1, p. 84-95, fev. 2010. Disponível em: <https://bit.ly/2q5Q7nu>. Acesso em: 31 jan. 2018.

PONIEWOZIC, J. Saving Chuck: dont't applaud, throw money. Time, New York, 23 abr. 2009. Disponível em: <https://ti.me/2KAqrbb>. Acesso em: 31 jan. 2018.

RECUERO, R. A conversação em rede: comunicação mediada pelo computador e redes sociais na internet. 2. ed. Porto Alegre: Sulina, 2014.

ROSE, F. The art of immersion: how the digital generation is remaking Hollywood, Madison Avenue, and the way we tell stories. New York: W. W. Norton \& Company, 2011.

SIGILIANO, D.; CAVALCANTI, G.; BORGES, G. Feminismo e TV Social: a repercussão dos telespectadores interagentes sobre o empoderamento de Dana Scully em The X-Files. In: CONGRESSO BRASILEIRO DE CIÊNCIAS DA COMUNICAÇÃO, 40., 2017, Curitiba. Anais... Curitiba: Intercom, 2017. p. 1-15. Disponível em: <https://bit.ly/2GxieCa>. Acesso em: 31 jan. 2018.

THE HANDMAID'S COALITION. The handmaid's guide. [S.1.], 2017. Disponível em: $<$ https://bit.ly/2rUG5q5>. Acesso em: 31 jan. 2018.

THE SYMBOLISM of the color red in The Handmaid's Tale. Vanity Fair, New York, 10 maio 2017. Disponível em: <https://bit.ly/2IvVCnn>. Acesso em: 31 jan. 2018.

VAGIANOS, A. Estas mulheres receberam Donald Trump vestidas como Offred, de 'Handmaid's Tale'. Huffpost, 6 jul. 2017. Disponível em: <https://bit.ly/2rVETTD>. Acesso em: 18 maio 2018. 
VAN ZOONEN, L. Entertaining the citizen: when politics and popular culture converge. Lanham: Rowman \& Littlefield, 2004.

WILlingHAM, A. Activists are using a decades-old novel as a protest. CNN, Texas, 27 mar. 2017. Disponível em: $<$ https://cnn.it/2JqK9WS $>$. Acesso em: 31 jan. 2018. 